\title{
Remote Monitoring and Alert System for Temperature Sensitive Products
}

\author{
Khalid Ammar \\ Department of Computer Engineering \\ Ajman University of Science and Technology \\ Ajman, UAE
}

\author{
Abdelrahman Gamal \\ Department of Computer Engineering \\ Ajman University of Science and Technology \\ Ajman, UAE
}

\begin{abstract}
Suppliers of temperature sensitive products are required by law to store and supply these products according to predefined temperature safe range [1], [2]. A suitable system that responds to the needs of food quality assurance inspectors have been developed and tested. The system is able to continuously monitor temperature sensitive products in food-chain supply such as production, processing facilities, transportation, distribution centers, stores, restaurants, etc. The system, continuously monitors the temperature remotely and report violations in real time to a server, minimizing the need of sending food inspectors regularly to the field.
\end{abstract}

Keywords: Remote sensing, Remote Monitoring, Temperature sensing, Cold storage, GSM Module, Microcontroller, Temperature Sensitive product.

\section{INTRODUCTION}

All temperature sensitive products (such as dairy products, meat, fish, etc.) require storage within a certain temperature safe ranges. Failure in maintaining the right temperature throughout the food chain can lead to medical significant problems. The proposed system provides a technology that adds an extra level of protection in monitoring and tracking this temperature remotely, the system continuously report any violation in real time. The system can be used in food-chain facilities therefore a quick action can be taken by food inspectors and food managers to preserve the safety and the quality of such products.

\section{THE IMPORTANT FEATURES OF THE SYSTEM}

- The system provides a reliability advantage compared to manual measurements, which rely on human intervention.

- The system minimizes the need of inspectors to keep visiting sites to check the efficiency of the cooling systems.

- The system provides 24 hour continuous monitoring without any interruption.

- The system flags temperature violations in real time.

- The system uses the existing mobile network.

- The system track the refrigerators history on PC.

- The system is easy to install, use and maintain; only Sensors [5], [6], Microcontroller [3], a SIM card, and a GSM [4] connection are needed at the field side. At the server side only a PC, Microcontroller, a SIM card, and a GSM connection are needed.

- The system is scalable and can handle any size of foodchain facilities.

\section{THE SYSTEM DESCRIPTION}

The system has been designed and implemented as a result of the integration of various hardware and software technologies. Figure. 1 illustrates the overall system functional block diagram. The system is divided into two main parts, a field side unit and a server side unit. The field side unit collects the temperature data and sends temperature violations messages to the server side. The server side unit receives the violation messages and stores them in the data base. We utilized the Adriano Mega 2560 board which comes with a high performance internal microcontroller ATmega2560 [3]. The board, along with DHT11 sensor and GSM shields, constitute our field side unit which communicates with the server side unit.

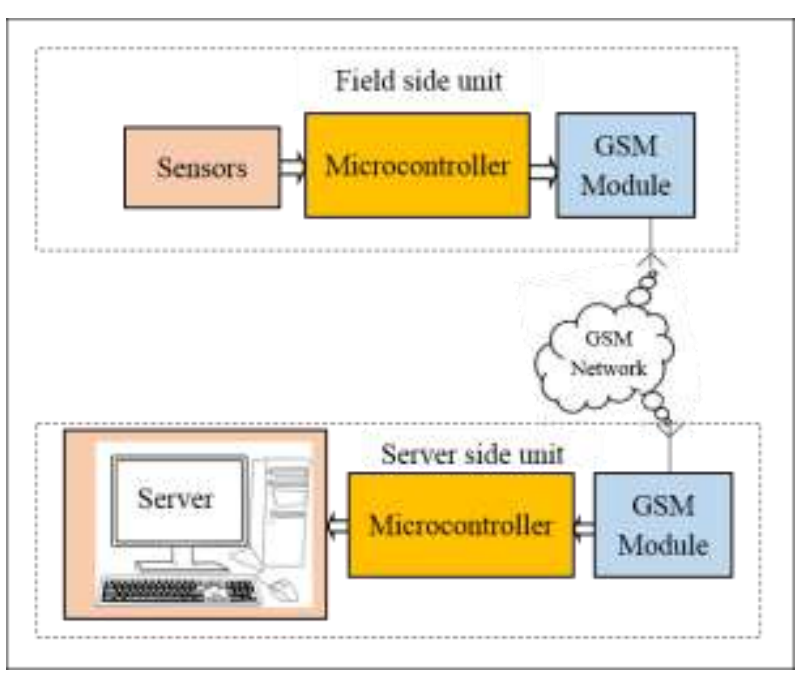

Figure. 1 The system functional block diagram. 


\subsection{The field side unit}

The field side unit of Figure. 2 is composed of a field side hardware module and a field side software module.

\subsubsection{The field side hardware module}

The field side hardware module consists of three sub modules, sensor module, microcontroller module and GSM shield module.

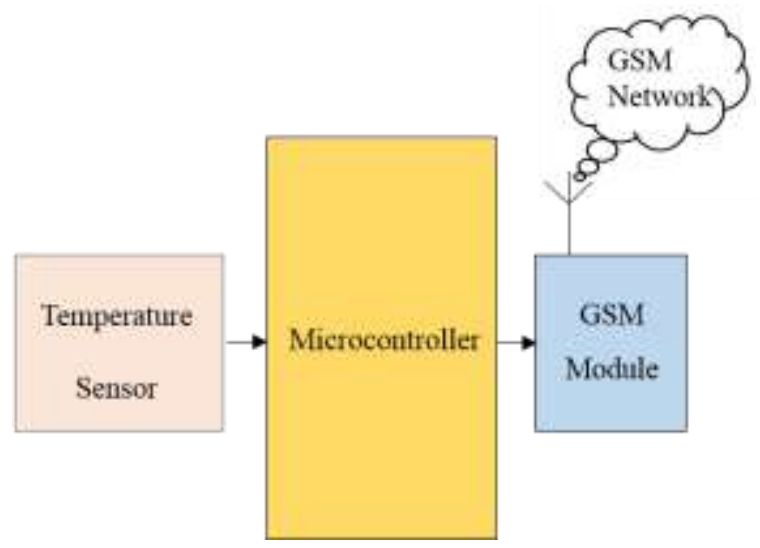

Figure. 2 Field side hardware Circuit diagram.

The microcontroller module with its embedded software collects the temperature data periodically from the sensors, compare it with the temperature set points provided by the user. If the temperature is not on the desired range, the microcontroller sends temperature violations messages to the server side via GSM/GPRS modem in real time.

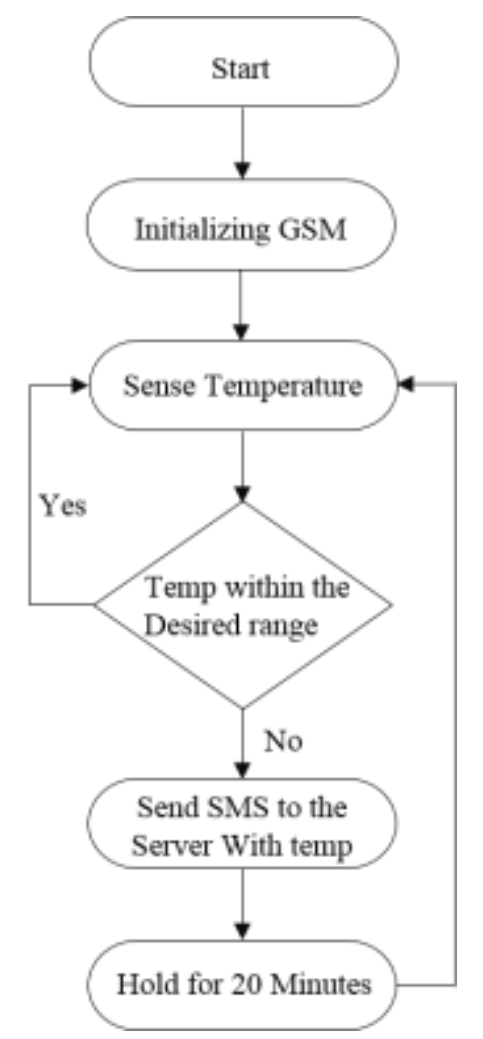

Figure. 3 The field side software flowchart

\subsubsection{The field side software module}

The field side software module is outlined in Figure. 3. The module initialize the GSM shield and connect the field side module to the network, after the module is connected to the network, the software module reads the temperature from the sensors. Each reading will be compared to a predefined desired temperature range. If the temperature is within the allowed range, it will take another reading, if the temperature is not within the allowed range, it will send a temperature violation message to the server including the temperature and the site ID. Figure. 4 shows an example of a violation message sent from the field side unit to the server side unit. The 32 digits identifier is a number that is stored in the microcontroller and also in the server, and it's used to identify that the message is received from authentic sender, if the same identifier does not exists in the message , the message will be discarded.

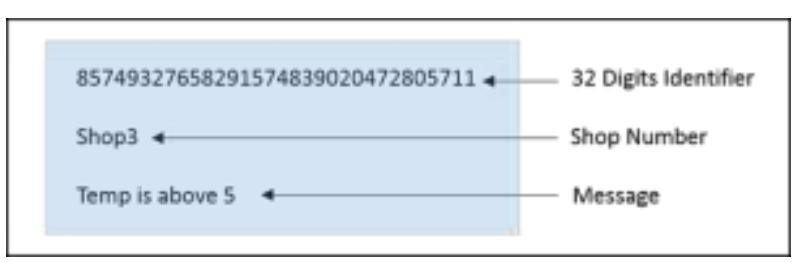

Figure. 4 Violation message example.

\subsection{The server side unit}

The server side unit Figure. 5 is composed of a server side hardware module and a server side software module.

\subsubsection{The server side hardware module}

The server side hardware module consists of three sub modules, the host computer module, the microcontroller module and the GSM shield module. The host computer acts as a server to run the server application program and to host the microcontroller and the GSM module.

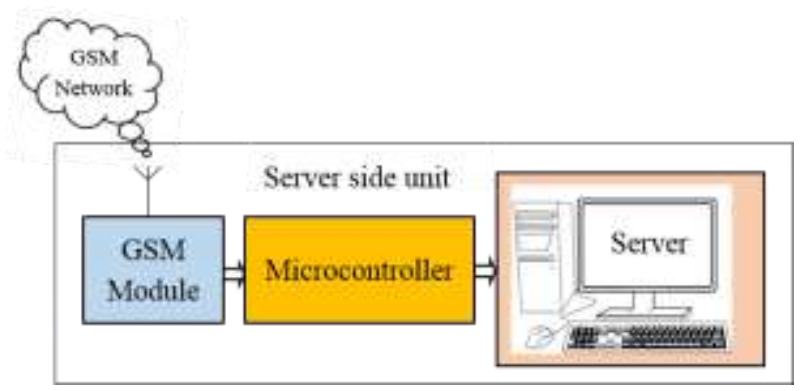

Figure. 5 The functional diagram of the server side unit.

\subsubsection{The server side software module.}

The server side software module consists of the microcontroller application program, the server application program, the database and the user interface. 


\subsubsection{The microcontroller and the server application program.}

The overall flow chart of the microcontroller application program and the server application program are shown in Figure. 6. Both codes execute simultaneously, the microcontroller code initializes the GSM shield and connect it to the network; after the GSM is initialized the microcontroller will be ready to accept the violation messages from the field side units, if a message received, the microcontroller sends the message to the host computer. As soon as the message is received, the host computer module software will save it on the data base
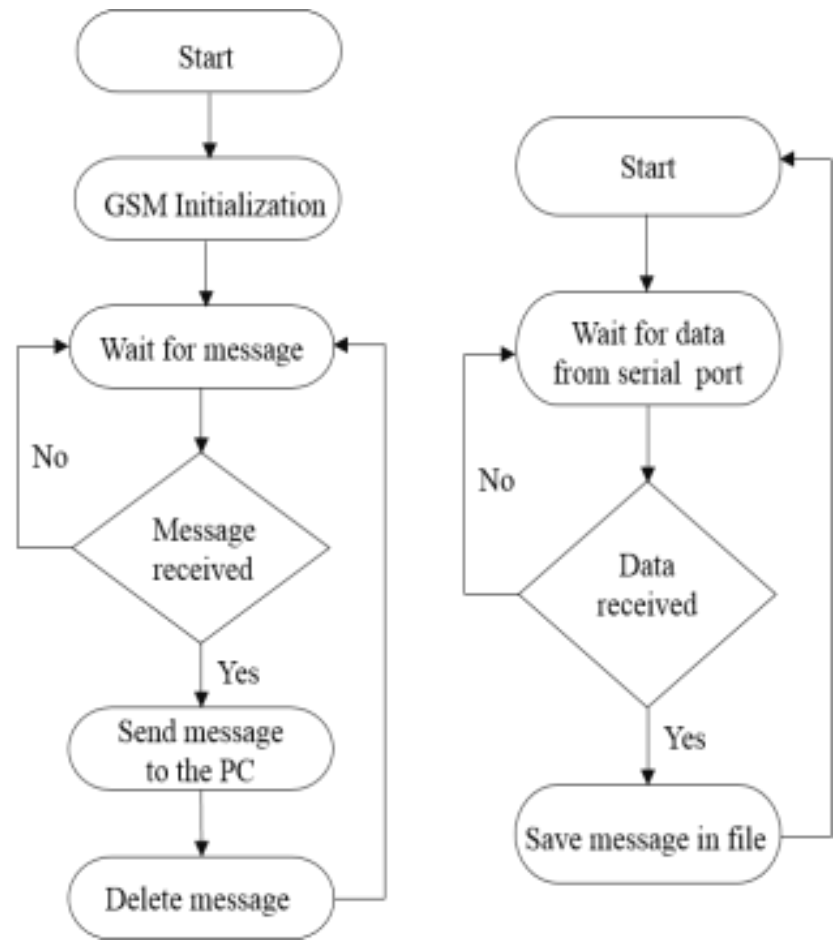

(Microcontroller software nodule)

(Host-Computer software nodule)

Figure. 6 The overall server side software module.

\subsubsection{The database.}

All of the temperature violations records are stored on a database for inspection. When the application initializes for the first time, a database will be created with a table called Shops-Table, this table saves the information of all shops. Table 1. shows a Shop-table, after adding a shop, another table will be created for this shop, to save the received violations and information. Table 2. shows a Violation table for specific shop, in this case shop number two.

Table 2. Shops table.

\begin{tabular}{|c|c|c|c|c|c|c|}
\hline 0 & SKSPD & SHOPUHE & Hopess & SWuger & DATEOFCOATOA & CEEI \\
\hline 123 & Seet! & Canर́fors & Ditad & $500172 \pi$ & $0906 / 5$ & 49E2 \\
\hline 120 & $\operatorname{sen} 2$ & Ster Houner & Striph & 50345556 & 090615 & 500 \\
\hline 128 & Sees & Soing & for & 500045 & $0466 / 5$ & 6773 \\
\hline
\end{tabular}

Table 2. Violations table for specific Shop

\begin{tabular}{|c|c|c|c|c|}
\hline NESACSID & 9090 & NESAS: & DATE, & TWE, \\
\hline 1 & Shepe? & Tencertare batone 5 & $20506 / 04$ & 17:0701 \\
\hline 2 & Shope? & Terpis below: & $201506 / 05$ & $2257: 97$ \\
\hline
\end{tabular}

Figure. 7 shows the main functions that interacts with the database. The Show function is used to retrieve information from the database, and the manage function is used to add and update the information into the database.

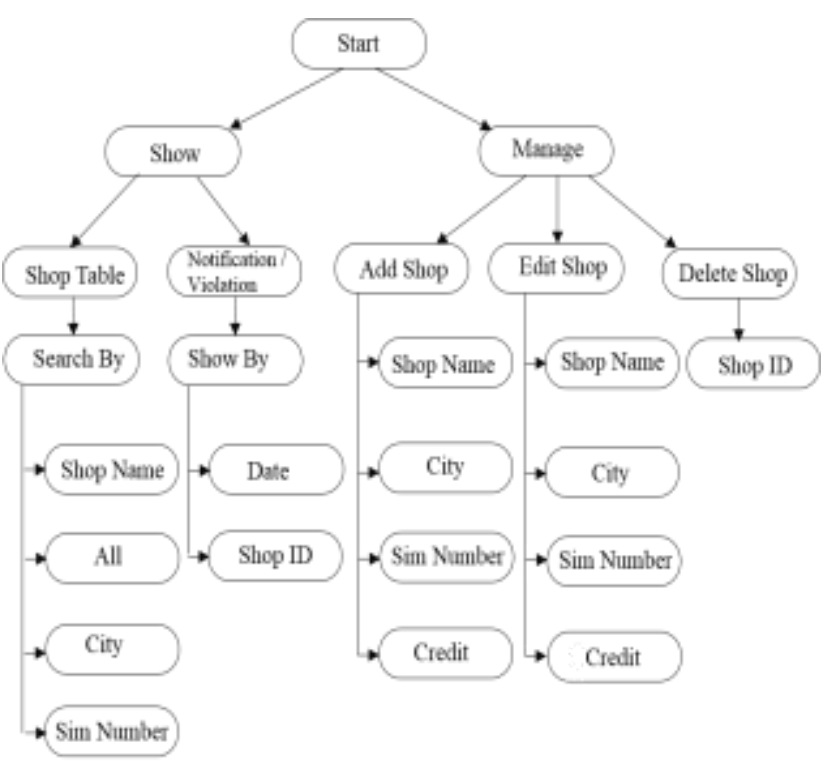

Figure. 7 Flowchart of the main functional that interacts with the database.

\subsubsection{The user interface}

A Graphical User Interface (GUI) have been developed to interact with the system by adding a site, editing a site, deleting a site and to locate the violation sites. Figure. 8 shows a sample of the GUI screenshots.

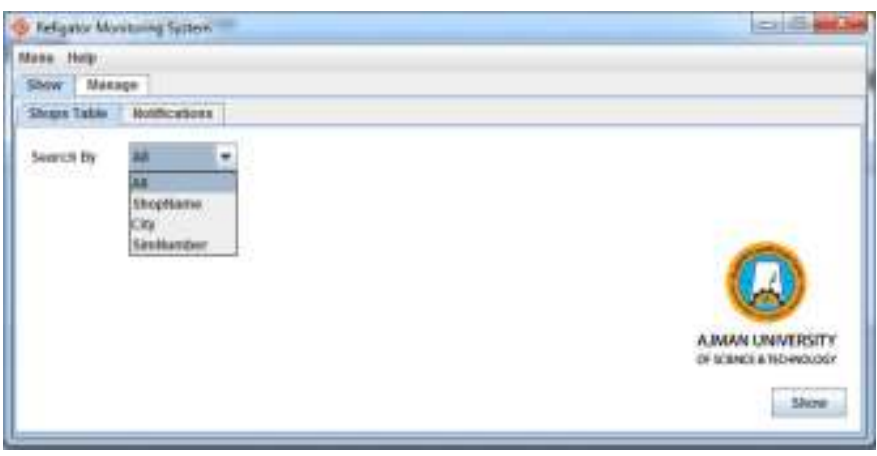


International Journal of Computer Applications Technology and Research

Volume 5- Issue 5, 245 - 248, 2016, ISSN:- 2319-8656

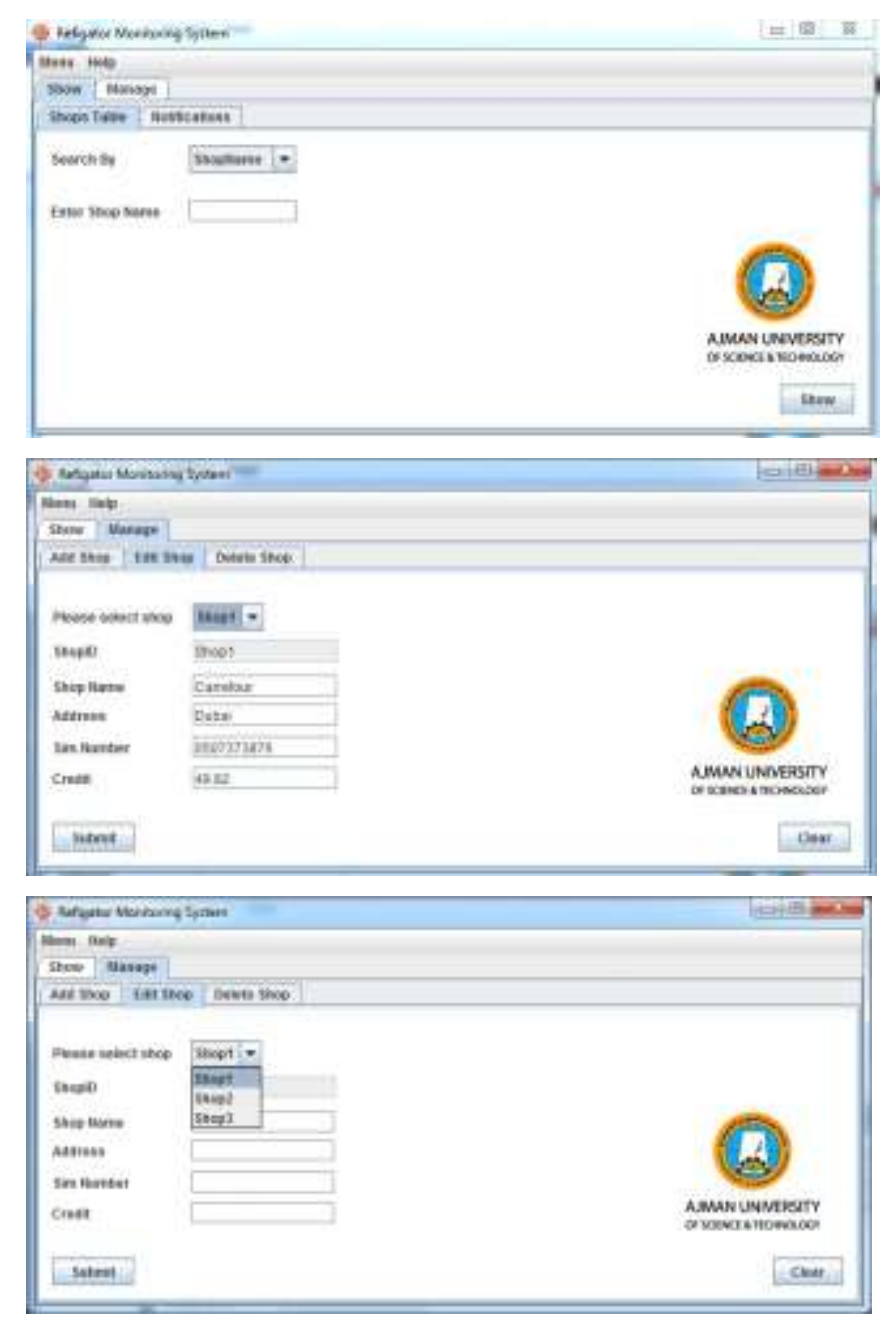

Figure. 8 Samples of GUI screenshots.

\section{REFERENCES}

[1] Food Safety Guidelines for Onsite Feeding Locations, Food Shelves and Food Banks.

http://www.health.state.mn.us/divs/eh/food/fs/foodbanks afety.pdf

[2] Storing Food at the Proper Temperature Fact Sheet. https://dmna.ny.gov/foodservice/docs/toolbox/storing_fo od.pdf

[3] Arduino Mega 2560.

http://arduino.cc/en/Main/arduinoBoardMega2560

[4] Arduino GSM Shield. http://arduino.cc/en/Main/ArduinoGSMShield

[5] DHT11 Temperature and Humidity Sensor. http://www.micro4you.com/files/sensor/DHT11.pdf

[6] DHT11 Sensor Connection with Arduino. http://playground.arduino.cc/main/DHT11Lib

\section{CONCLUSIONS}

The cold storage monitoring and alert system is an indispensable tool for food managers and food inspectors. A cold storage monitoring and alert system has been fully designed and developed in house. The system provide an extra level of protection in monitoring and tracking temperature violations for temperature sensitive products remotely at any time. The system has been tested successfully against different temperatures violation setups. The system hardware and the application software's worked in harmony by taking readings from temperature sensors and sending violations to the server. The server application makes it easy for the user to retrieve and view those violations. 